\title{
From solitude to solicitation: How people with intellectual disability or autism spectrum disorder use the internet
}

\author{
François Sallafranque-St-Louis ${ }^{1}$ \& Claude L. Normand ${ }^{2}$ \\ ${ }^{1}$ Centre intégré de santé et services sociaux de l'Outaouais, Gatineau, QC, Canada \\ ${ }^{2}$ Université du Québec en Outaouais, Gatineau, QC, Canada
}

\begin{abstract}
Very little is known about how people with intellectual disability (ID) or autism spectrum disorder (ASD) use the Internet. However, we do know that many of them have limited social circles. Electronic social media could facilitate the development of relationships, increase social participation and reduce social isolation for these people. However it may also expose users to unwanted encounters. Our exploratory study attempts to get a glimpse of Internet experiences of young adults with ID or ASD. Eight participants (five with ID and three with ASD) whose mean age was 25 years participated in this preliminary study. A sociodemographic and Internet use questionnaire was administered with the help of the participants' support worker. Seven participants agreed to be interviewed by one of the researchers in a separate meeting, in the presence of their support worker. Results show that all participants enjoyed using the Internet for communicating (e.g. Facebook, e-mail, chatrooms, dating sites) or entertainment (e.g. watching videos, listening to music). Three male subjects played games online, and only participants with ASD (without ID) created content (e.g. website or blog). All interviewees with ID and two of the three with ASD had distressing experiences including: being insulted online, having false rumors spread, receiving threats or being targets of sexual cyber-solicitation. Users with ID have had to rely on friends, parents or social workers to avoid or rectify cyber-victimization episodes. Internet access has opened a wide window of opportunity for people with ID and ASD, but more education and support is needed to ensure safe and positive Internet use by this population.
\end{abstract}

Keywords: Internet; social networking; sexual solicitation; intellectual disability; autism

\section{Introduction}

It is estimated that three billion citizens worldwide use the Internet and that one third of the earth's inhabitants will be using smartphones by the year 2017 (Internet World Stats, 2016). Cyberpsychology researchers believe that the Internet, especially social media (e.g. Facebook, Second Life), enable people to broaden their network of friends, receive support, forge positive identities, and participate fully in their real and virtual communities (Amichai-Hamburger, 2013; García-Galera, Del-Hoyo-Hurtado, \& Fernández, 2014; Moisey \& van de Keere, 2007; Raghavendra, Newman, Grace, \& Wood, 2013; Subrahmanyam, Greenfield, \& Brendesha, 2004; Ybarra, Mitchell, Palmer, \& Reisner, 2014). However, very little is known about Internet use by people with ASD or ID especially (Caton \& Chapman, 2016; Hoppestad, 2013; Lussier-Desrochers, Dupont, Lachapelle, \& Leblanc, 2011; Normand \& Sallafranque St-Louis, 2015; Sallafranque St-Louis \& Normand, 2011). Caton and Chapman's (2016) recent review on the use of social media shows not only that research in this area is sparse, but also that research 
methodologies are weak. Generalizations cannot be made and the question of how people with ID use social media can be answered only partially, and cautiously. The absence of comparison groups limits any interpretation regarding the particularities of Internet use by this segment of the population.

This paper reports preliminary results from an exploratory study of Internet use by young adults with neurodevelopmental disorders; more specifically, intellectual disability or autism spectrum disorder. First, we shall review available data on Internet use by people with intellectual disability, then present the risks associated with online communication in this population. Our research questions ask: 1- How do young adults with intellectual disability or autism spectrum disorder use the Internet? and 2- Have they experienced online sexual solicitation? Our qualitative research method is presented next. Results, illustrated by quotes from interviews, are divided into three sections: 1- Internet access and use, 2- online social networks, and 3-online sexual solicitation. A discussion closes, with suggestions for future research as well as recommendations for intervention.

\section{Internet Use by Adults with ID}

The rare studies on Internet use by adults with ID show that information and communication technology is important to them, to forge their identity and find a place in which they belong to a social network. Adults who were interviewed, in the few studies published, like social networking sites (SNS) particularly for keeping contact with parents and friends, making new friends, and giving and receiving support (Holmes \& O'Loughlin, 2012; Löfgren-Mårtenson, 2008; Molin, Sorbring, \& Löfgren-Mårtenson, 2015; Shpigelman \& Gill, 2014). The majority of participants from Shpigelman and Gill's (2014) study also reported finding it easier to make new friends by Internet and being more comfortable communicating online than face to face. Furthermore, adults with ID say that the Internet provides them with a (cyber)space where they can escape their parents' or caseworkers' control and be more self-determined. On the Web, they are freer to "go" where they want and make friends with whom they want, unseen by their guardians and caregivers (Löfgren-Mårtenson, 2008). They can describe their activities and express their feelings in blogs or other social media (McClimens \& Gordon, 2009; Shpigelman \& Gill, 2014).

People with disabilities are more likely than their non-disabled counterparts to have narrow personal and social networks. For people with intellectual or developmental disabilities, these relationships are often limited to other people with similar disabilities, family members and members of their paid support staff (Cambridge et al., 2002; Clement \& Bigby, 2009; Forrester-Jones et al., 2006). In Sweden, parents and teachers in special programs for young adults with ID (18-20 years old) describe their students as socially isolated. They add that the Internet has become a very important tool for these youth, some of whom have networks of online friends whom they have never met offline (Löfgren-Mårtenson, Sorbring, \& Molin, 2015). Moreover, their students use the Internet for multiple purposes, including writing a blog, chatting, socializing and searching for friends (Molin et al., 2015). They use it also for finding information, listening to music and watching videos.

People with ID believe that participating in social media, like Facebook (FB), helps them "feel like everybody else" and gain a greater sense of belonging (Kampert \& Goreczny, 2007; Löfgren-Mårtenson, 2008; Shpigelman \& Gill, 2014). It is thus advisable and possible to increase activity of people with ID in the digital world thanks to support from the people around them (Chadwick, Wesson, \& Fullwood, 2013; Seale, 2014). This support would help them through their difficulties building broader, further-reaching social relationships. For example, paired with university students, adults with ID learned to create their own blog (McClimens \& Gordon, 2009), or to share photos and comments on Flickr (Kydland, Molka-Danielsen, \& Balandin, 2012). Raghavendra and colleagues (2013) taught Internet use to adolescents with cerebral palsy or traumatic brain injuries who had limited circles of friends, in the hope of expanding their social networks. They designed individualized intervention plans based on these youth's and their families' needs and interests regarding computer knowledge. In the end, a strong increase in interpersonal communications and in the number of online contacts, but also large variations between the subjects, were found. First, 11 of the 16 participants had never communicated online before. When the project ended, they were all using some form of online communication (e.g. email, Facebook, Skype), with an overall average of 38 people (range: 4-170). Furthermore, their score on a loneliness scale decreased slightly a few months post-intervention (Raghavendra et al., 2013). 


\section{Risks Associated with Online Communication}

Several studies on people with ID highlight risky situations during Internet use, especially social networking sites (Holmes \& O'Loughlin, 2012; Löfgren-Mårtenson, 2008; Molin et al., 2015). They mention the combination of a desire to make friends and be liked with a vulnerability to exploitation and violence, a wish to be socially desirable, and a tendency to be agreeable, which are typical of many people (especially women) with ID. For instance, youth and adults with ID say they accept FB friend requests only from people they know or recognize (Molin et al., 2015). However, their number of FB "friends," which is in the hundreds, and their conflicting statements ("I look at the person's photo and if he or she looks honest...") suggest otherwise. Holmes and O'Loughlin (2012) use clinical vignettes to describe how the desire to make friends can lead to a loss of control. For example, one 30-year-old woman with a mild intellectual disability would accept any FB friend request received and thus accumulated more than 600 "friends." They included a man who extracted over $\$ 100$ per month from her and others who would make fun of her appearance or sexually harass her. Another young woman, with autism and a mild intellectual disability, took the word "friend" literally and would attend parties where she was ignored by her so-called friends. Statements from the interviews by Löfgren-Mårtenson (2008) of young adults with ID suggest that they understand the risks related to meeting strangers on the Internet (e.g. money theft, sexual exploitation). Nonetheless, she hypothesizes that these adults simply repeat the safety measures that they were taught, but do not remember them on the spur of the moment. Perceiving a potential "friend," they accept danger and abuse. She believes that the greatest danger perceived by people with ID is to be isolated and deprived of romantic relationships.

Normand and Sallafranque St-Louis (2015) identified the variables associated with sexual cyber-solicitation of youth published in the scientific literature. Their review shows that past or present sexual or physical abuse, social isolation, loneliness, depression and chatting increased the likelihood of falling prey to sexual cybersolicitation. Sadly, all variables except for chatting time tend to be more prevalent among people with ID or ASD than in the general population (Brereton, Tonge, \& Stewart, 2006; Khemka \& Hickson, 2000; Mandell, Walrath, Manteuffel, Sgro, \& Pinto-Martin, 2005; McGillivray \& McCabe, 2005; Murphy \& O'Callaghan, 2004; Nettlebeck \& Wilson, 2002).

This vulnerability, combined with the social media craze, worries parents of adolescents or young adults (with or without any disability) and caseworkers in school environments and in health and social services (Chadwick et al., 2013; Holmes \& O'Loughlin, 2012; Löfgren-Mårtenson, 2008; Löfgren-Mårtenson et al., 2015; Molin et al., 2015; Seale, 2014). Their concerns include: 1 - exposure to inappropriate content online, including pornography (Dowdell, 2013; Löfgren-Mårtenson et al., 2015); 2- harassment and cyberbullying (Buijs, Boot, Shugar, Fung, \& Bassett, 2016; Didden et al., 2009; Guan \& Subrahmanyam, 2009; Suzuki, Asaga, Sourander, Hoven, \& Mandell, 2012; Wells \& Mitchell, 2014; Ybarra, 2004; Ybarra et al., 2007); 3- excessive use of or addiction to the Internet (Blaya, 2015; MacMullin, Lunsky, \& Weiss, 2016; Young, 2009); 4- sexual cyber-solicitation (Buijs et al., 2016; Guan \& Subrahmanyam, 2009; Noll, Shenk, Barnes, \& Haralson, 2013; Noll, Shenk, Barnes, \& Putnam, 2009; Molin et al., 2015; Wells \& Mitchell, 2014; Ybarra, Espelage, \& Mitchell, 2007); 5- maliciousness and abuse, including sex, violence and theft, when online communications with strangers lead to in-person meetings (Buijs et al., 2016; Dowdell, 2013; Löfgren-Mårtenson et al., 2015; Noll et al., 2013; Noll et al., 2009); and 6- prosecution of young people who do not see the negative or serious consequences of their online actions or statements, including harassment, defamation, threats, or sexual solicitation (Löfgren-Mårtenson et al., 2015).

Additionally, a few studies having received much media attention showed a possible link between excessive use of the Internet and various mental health disorders, including addiction, depression, anxiety, attention deficit disorder and hyperactivity (see Ho et al., 2014 for a meta-analysis). Despite the absence of a cause-effect relationship in these correlational studies, it has been suggested that the Internet would be causing the problem by inducing various mental health problems. Yet, the reverse may also be true: mental health problems could push people to spend more time online. For example, Ybarra and colleagues (2014) showed that a larger proportion of youth who are targets of bullying in real life exhibit symptoms of depression, while also being victims of online bullying.

Nonetheless, some concerns are well-founded; youth receiving special education services reportedly have more online sexual contacts than their peers (Helweg-Larsen, Schütt, \& Larsen, 2012; Wells \& Mitchell, 2014) and poor 
cognitive skills are seemingly linked to higher-risk online behaviours (Noll et al., 2013). From 9\% to over $40 \%$ of minors who use the Internet have had face-to-face meetings with people who were online acquaintances first. In $30 \%$ to $61 \%$ of these cases, their parents were not aware of these meetings (Baumgartner, Valkenburg, \& Peter, 2010; Helweg-Larsen et al., 2012; Livingstone, Haddon, Görzig, \& Ólafsson, 2011). There is thus concern about the safety and well-being of people with cognitive or socio-emotional limitations who spend a lot of time on the Internet, particularly on SNS. Clearly, the desire of young adults with ID to meet their soulmate motivates their use of social media and online dating sites (Löfgren-Mårtenson, 2008). It should be further noted that they are generally seeking a partner online in view of developing an offline relationship with someone who, preferably, has no disability.

Our study aimed to answer the following questions: 1- How do young people with intellectual disabilities or autism spectrum disorders use the Internet?; and 2- Have they experienced online sexual solicitation? More specifically, participants were asked about ten common online activities (e.g. e-mail, watching music videos, social media), negative online experiences such as cyberbullying, before finally touching upon the topic of online sexual solicitation.

\section{Methods}

\section{Procedure}

This study received ethical approval from the Université du Québec en Outaouais's ethics committee, as well as the CÉRC-CRDITED ('Intellectual Disability and Autism Spectrum Disorder Rehabilitation Centres' Joint Ethics Committee"), a province-wide, designated ethics committee for research with vulnerable populations. Given that the study interview focused in part on sexual cyber-solicitation, for ethical and legal reasons, minors were excluded from the study. We wished to avoid placing our doctoral student (F.S.S.) in a position in which he would have to report to authorities any form of sexual solicitation or abuse that could have emerged from the interviews. Additionally, the interviews took place in the presence of the participants' support worker. We assumed that he or she would be in a position to detect any discomfort necessitating we put an end to the interview, ask for renewed consent to go on, or offer support and take appropriate action if sexual abuse unknown to the rehabilitation centre staff was revealed.

Study participants were recruited by support staff from a regional rehabilitation centre devoted to intellectual disability and autism spectrum disorder in the Outaouais region (population approximately 386,000 ) in the province of Quebec, Canada. The rehabilitation centre policy and research committee requested that managers forward information about the study to their clinical staff by e-mail, inviting them to refer to the principal investigator any client from their caseload that may be interested to participate in this study. Inclusion criteria were that the participant: 1- be over 18 years of age, 2- use the Internet at least once a week, and 3- be able to understand and answer questions read to them from a questionnaire. To take part in the interview, they were required to communicate well enough verbally to be understood.

Support workers explained the study and guided the participants through an illustrated consent form, written in simplified language according to published guidelines (Giard \& Morin, 2010). This form ended by asking participants if they would be willing to meet again for a one-hour interview with a doctoral student or principal investigator. After consenting, clients received a written questionnaire to fill out from the support staff, who read the questions aloud to them. Next, they or the participant answered the questions in writing.

Upon receiving the signed consent form agreeing to the interview, the principal investigator arranged for an interview, which took place wherever the participant preferred (i.e. usually at home, or at one of the rehabilitation centre's sites.) Verbal consent was requested again before beginning the interview, and subjects were told they could withdraw their participation or refuse to answer any question, at any time.

\section{Sample}

At present, a total of eight adult subjects have been forwarded to the researchers. Five (three males, two females) had a mild ID, and the three others (two males, one female) had ASD (without ID). Their ages ranged 
from 19 to 40, with a mean age of 25 years. Four participants lived with their parents, two in group homes, and two, independently with their life partners. Five worked part-time, while three were seeking employment. Two were also studying, in an adult education facility or by distance education. Four lived in a rural area, three in the city, and one is unspecified. Questionnaires were filled out by all participants, but one male subject did not want to follow up with the interview.

\section{Measures}

A mixed method was chosen for this preliminary study of an exploratory nature. Quantitative data were collected through a questionnaire, while an interview provided supplementary qualitative data on the same topics. The questionnaire was designed to provide descriptive data on Internet use by people with ID or ASD, but also to select the most diverse sample possible for interviewing, in order to aim for data saturation in the content analysis. For example, on the basis of sociodemographic information, we hoped to include in our sample male and female subjects, from rural and urban areas, employed and unemployed, in various living arrangements, etc. The same strategy was to be applied with their answers to Internet use (e.g., e-mail, social networking sites, gaming, etc.).

Questionnaire. The first part of the questionnaire focused on standard sociodemographic information (age, gender, employment status, education, and living arrangement). The second part concerned Internet use. The research questions were read aloud to participants by their support worker. Four participants answered in writing themselves, while the other four required or asked their support worker to write down their answers. They answered yes or no to a list of ten common online activities they might perform (i.e. search for information, read or send e-mails, use social networking sites, play games online, shop, make new friends, subscribe to dating sites, look at pornography, watch movies, and other - to be specified), and what they enjoyed the most about Internet. Then they were asked about cyberbullying (four items) and online sexual solicitation (four items). These eight questions were taken from the Youth Internet Safety Survey (see Ybarra et al., 2007). An open-ended question asked if they had had other types of negative experiences online and, if so, to describe them. Finally, they were asked if they had met face to face with someone they knew only online and, if so, whether they told anyone about it beforehand.

Interview. A semi-structured interview was conducted to gather more detailed information about the people's experiences online, but also to compare their offline social life with their online social network. The interview guide consisted of five sections with approximately two open-ended questions per topic pertaining to: 1-family, 2- friends, 3- self, 4- love and sexual relationships, and 5- navigating the Web, eventually broaching the subject of sexual cyber-solicitation.

\section{Data Analysis}

Questionnaire data were analyzed using descriptive statistics. Interviews were recorded and transcribed verbatim. A content analysis was performed using a mixed categorization approach. An inductive approach was chosen to allow categories to emerge (Blais \& Martineau, 2006; Paillé \& Mucchielli, 2012) while predetermined categorization was based on our knowledge of Internet use in other populations, particularly those associated with cyberbullying and online sexual solicitation. Data triangulation and a back-and-forth analysis were conducted between the raw data and the categories (emerging or predetermined) based on discussions between the two authors (Stake, 2006). These analyses were chosen to ensure credibility, generalizability and reliability in our interpretations (Gohier, 2004).

\section{Results}

The results are presented in three sections. The first two sections present results pertaining to the question, "How do young people with intellectual disabilities or autism spectrum disorders use the Internet?" The third section refers to our second research question, which concerns online sexual solicitation. The results are enhanced by quotes from the interview transcripts. Any names that appear have been changed to prevent study participants from being identified. 


\section{Internet Access and Internet Use}

Study participants accessed the Internet through personal computers (no tablets) at home. The two participants living in a group home had to visit the public library to use a computer and go online, but for different reasons. As one young man explains:

Interviewer (I): OK, so you don't have a computer in your room?

Participant (P): No. Not for now. Only outside the house.

I: OK, is it a rule over there [in the group home], or do you prefer it that way?

$P$ : No, it's a house rule.

Our oldest female subject states:

I: Ok, did you ever have Internet at [the group] home?

P: No. I don't want it.

I: No? Why not?

P: Because I would not sleep at all!

I: I see... You think you would get hooked? Are you allowed where you live right now?

$\mathrm{P}$ : I would be allowed, but it's expensive. And, I don't have the money for it.

It is noteworthy that one young man's problematic computer use (i.e. masturbating in front of young girls through his webcam) led his parents to confiscate his portable computer. This does not mean he is excluded from the online community; he revealed being able to access the Internet...by visiting his uncle and borrowing his computer!

Only the youngest female subject owned a smartphone. Three others had previously had one, but no longer did. In two cases, they were denied access following negative experiences (such as sexual solicitation) through texting or sending images. Although three male participants had the technology to connect to the Web through their game consoles, they used these only for playing games (offline).

The study participants' online activities are presented in Table 1 from the most to the least popular. Clearly, the main purpose of going online is to connect with people. All study participants had at least one Facebook profile, and more than half were using, or had previously used, multiple dating sites.

Table 1. Number of Participants Performing Each of 10 Online Activities.

\begin{tabular}{ll}
\hline Internet Use & Participants $N$ \\
\hline Social networking sites (e.g. Facebook, Twitter, etc.) & $8 / 8$ \\
E-mail & $7 / 8$ \\
Make new friends & $7 / 8$ \\
Search for information/images & $6 / 8$ \\
Shopping or browsing for merchandise & $5 / 8$ \\
Dating sites & $5 / 8$ \\
Video streaming & $4 / 8$ \\
Online gaming & $3 / 8$ \\
Watch pornography & $3 / 8$ \\
\hline
\end{tabular}

When asked if they searched for information online, participants described looking for what could be labeled "representations of objects." For example, Native art to draw inspiration for her own artwork, fossils for one interested in dinosaurs, or memorabilia from retro movies, TV shows, or games. Shopping was restricted to two participants with credit cards. In one case, online purchases largely exceeded the man's financial means. Three others merely looked at merchandise available in stores. Gaming and pornography were restricted to the men. 
Only subjects with ASD (without ID) mentioned other Internet uses. One participant spoke of video communication technology as an important tool to stay in touch with loved ones. It was the ideal way for her to "talk" with her father, who lived nearly $5000 \mathrm{~km}$ away, as well as with an offline friend living in another country. Another unique case was a man who had created websites for his two small businesses (i.e. selling clothing and picking up refundable empty cans and bottles.)

\title{
Online Social Networks
}

All participants declared Facebook (FB) their preferred social networking site (SNS). One participant with ASDthe youngest and only one with a smartphone-admitted being online practically night and day. She was the only person in our sample with other SNS accounts, namely Twitter, Instagram, Pinterest, and Snapchat. Yet she said FB remained her favourite. In this section, we focus on two aspects of online social networks. First, we describe the composition of these networks. Second, we examine which activities are performed on FB.

Composition of online social networks. Study participants reported having from 20 to more than $400 \mathrm{FB}$ friends (mean $=169$ ). These friends included mainly close family members (i.e. parents, siblings) and extended family (e.g. aunts, uncles, cousins). Also included were some friends from school, work or the community at large, as well as what participants qualified as acquaintances. Only one (female) participant revealed having an FB network consisting of "three quarters people with ID." As one young woman stated:

\author{
I: Ok, so who are your Facebook friends? \\ P: Well, like, I have, like, acquaintances, like Karen, Sophie, I have lots of people. \\ I: Well, these people, your Facebook friends, are they people you see often? \\ P: No. I used to before, but not now. \\ I: Ok, so what happened? \\ P: Well, we lost contact, that's all. \\ I: Life does that sometimes. How had you met them? \\ P: Well, on the job, my former job.
}

Having a large number of FB friends can seem surprising since these subjects reported having very few, if any, friends offline. This explanation by one male participant reflects the experience of many of our interviewees.

P: But I don't write to them. I don't talk to them. We're just friends like that.

..

I: But, if you have 400 friends, you must get a lot of news from these people? These people, had you met pretty much all of them before...? How did you manage to become friends with all these people on Facebook?

$\mathrm{P}$ : Some of them I recognized, but some of them...

I: Ok, so that's it... They have their picture [on Facebook] so you go "Oh yeah, him or her, I've met them before."

P: Some yes but some no.

I: No, but you accepted them?

$\mathrm{P}$ : Yeah. But I don't talk to them!

....

I: Sometimes [FB] suggests "People you may know." You check whether you know them, then you send a friend request?

P: Yeah.

I: So it works both ways? Some people send you requests and you too you send requests when you recognize them?

P: If they're family relatives, I will send them friend requests.

I: You mostly ask people you know or recognize... or someone who looks interesting, you'll ask him?

P: If someone looks interesting, l'll ask him.

Having a wide network of FB friends is therefore no guarantee of having a true relationship or even any contact with them (besides having access to their profiles). The loneliness and social isolation that participants with ID experience in real life is reflected in their online experience. 
Two of the three participants with ASD differed from those with ID in the composition of their online social networks. FB was used to entertain close ties with only a few select friends or relatives, some of them hundreds of kilometers away.

How Facebook is used. Our participants described a variety of purposes for FB, the most common being a combination of staying in touch and seeking entertainment. Respondents like to see what other users post on their pages, and only a few of them publish their own content. Other common uses are 1- maintaining longdistance relationships and 2- receiving emotional social support; and, as reported only by participants with ASD, 3- joining specific groups based on their interests; or 4- using FB as a messenger when preparing for school or for work.

Maintaining long-distance relationships. As mentioned above, relatives are an important part of the online social network of participants with ID or ASD. Facebook helps them keep in touch with relatives whom they may be unable to visit otherwise. For example, after his mother's death, one young man moved away from his maternal grandparents and other relatives, to live with his father in a distant city. When describing his online contacts, here is what he had to say:

P: Well, many of them [FB friends] are on my mother's side of the family. There are also many from my father's side [who live far away].

I: Do they write to you? Do you...?

$\mathrm{P}$ : Yeah.

I: Yeah, so you stay in contact with them that way?

P: They ask me how I'm doing.

One female participant said that SNS have afforded her an opportunity to become closer to extended family members with whom she had had little contact before. Like many others, she tends to use FB to send private messages, similar to e-mails.

P: I have first cousins, second cousins, aunts and uncles.

I: Ok, so why did you add them to your Facebook?

$P$ : Since I'm using it, might as well get closer to the family.

The 40-year-old participant had lost touch with her friends after graduating from high school. Thanks to FB, they were able to reconnect.

$\mathrm{P}$ : We found each other again because of FB. Because we knew each other, but we had not been in touch for so many years. When I posted my picture on FB, they said, "Hey! I know this girl! I went to school with her!" So now all my school friends, and half of the friends from school that I knew, we [met/found] each other again on it [FB].

Clearly, SNS are connecting people and enabling them to communicate, but to varying degrees of intimacy. They also allow them to maintain and nurture long-distance connections that might have been dropped in another era (of letter writing).

Receiving emotional social support. One (male) participant openly revealed on FB that he was gay. He mentions receiving positive feedback for "coming out." Another young man said he tended to turn to FB when he felt bored, lonely or angry. He admitted to feeling lonely "really, really, but really very often," especially when school is out for the summer. Under these circumstances, he can spend "two, three, maybe even four [hours] on FB."

Having published suicidal thoughts once in the past, he received support and comfort on FB from a longdistance friend. "The first one to react was my best friend [who lives in another town and whom he can see only a few days per year while on vacation]. That, that... that's really what surprised me the most. That he was the first one to react." 
Another example of social support provided through FB was reported by one woman, as described below.

P: Some people are surprised, because a 40-year-old woman like me who expresses herself a lot and says what she does in a day, not many people would do it.

I: Ok, so they think you accomplish a lot?

$\mathrm{P}$ : Yes.

I: And when you hear positive comments like that... yes, that makes you happy. (She smiles).

$\mathrm{P}$ : The "happy face" comes up right away!

I: You're proud of yourself?

P: Yes. I feel better and it makes me want to go forward.

Publishing content, pictures or comments on FB may be a way to gather social support or recognition. However, while only one participant with ID reported being an active content "creator," this use was common to all three participants with ASD.

Joining specific groups. FB allows its users to join groups with common interests or opinions and to be alerted of conversations taking place within these groups. No participant with ID reported having joined such a group, yet all three with ASD did. The limited interests of a quasi-obsessive nature typical of people with ASD appear to be fertile ground for such a purpose. Our female participant with ASD reported being "obsessed" by one of these FB pages. Another participant, hooked on horror movies, said, "if you want to know... what we do most often during the time when we're [chatting] on that inbox is to tell each other horror stories."

Preparing for school or for work. Contrary to the majority of our participants, one young man with ASD did not use FB for socializing. He had created his FB profile with practical considerations in mind.

P: I figured it would be useful since most of my colleagues [from work] have an FB [profile]. So, they could give me the [work] schedule on FB instead of on my Hotmail.

I: OK, so this is what motivated you to have one [an FB account]?

P: Yeah. The usefulness that I could use it, instead of just socializing with people.

He also took advantage of an FB function to create an instant messaging group to open up conversations with schoolmates to prepare for class.

In summary, FB appears to alleviate social isolation and loneliness, at least on the surface. It is easy and gratifying to accumulate large numbers of FB friends. It is entertaining to watch what these people are doing by looking up their FB pages. But our participants' accounts show that for these friendships to develop online, they must (pre)exist offline. Otherwise, FB friends are statistics and content creators, with no affective connection and no personal communication to the users with ID. Users with ASD appear to be more discriminating with their FB friend requests. Although rarely done, reaching out and communicating feelings online can allow emotional social support to emerge, from strangers met online, but more likely from closer friends.

\section{Online Sexual Solicitation}

Not all online activities are positive or neutral; some can cause distress. Reports from study participants show that six out of eight (all three women and three of the men) were insulted, mocked, or threatened online. Six participants (including the three women and one gay man) had agreed to meet offline (in the person's home, a bar, or a motel) with a stranger they had met online without notifying anyone of this meeting. Six of our subjects (including the three women) had experienced some form of unwanted sexual solicitation online. Three had been asked to talk about sex against their wishes, four to share sexual information or sexual pictures of themselves and four, to perform a sexual act in front of their webcam ${ }^{1}$.

Here are excerpts from different interviewees:

I: And when he was online, what did you talk about? Did he write to you on the Internet?

$\mathrm{P}$ : He always wanted me to send him pictures of my breasts. 
I: Sometimes, if they asked you for things you did not want, were you able to...

P: Yeah. They wanted me to show them my buttocks or my anus. I said "No. I don't do that!"

I: You always communicated by computer?

P: Yes, and by phone also... By cell phone. He would send text messages.

I: OK. Did he send you sex texts? Sexual texts?

P: Like... It sounds stupid, it's also disgusting, but he sent a picture of his penis when it had sperm on it.

I: Did anyone ever write to you on the Internet and ask you to do sexual stuff?

$\mathrm{P}$ : Yes, but I always refused.

I: And, how did he write to you? On which site? Was it on Facebook?

$\mathrm{P}$ : Well, some on Facebook, and others it was on dating sites.

These types of requests were from strangers in all cases but one. Only one woman had first met the man in person, before engaging in an online relationship and receiving disturbing sexual requests from him.

This unwanted sexual solicitation, although on a virtual platform, has real consequences in the lives of these victims.

\section{I: How did you feel then?}

P: Well, I felt like a nobody, less than a nobody, it was anyone, any time, in any way...

I: So, you felt like this when you would receive [sexual] pictures like that?

$\mathrm{P}:$ Yes, it was like I was encouraging them to continue, and then...

I: And then they would insist?

P: No, it's as if I accepted their photos. Well it's like, it's as if I was saying "well, I'm interested in their photo," well, I'll keep doing it [the abuser says to himself], but it's not true!

In one case, the online relationship evolved into an abusive and violent long-term relationship, which ended only when, fearing for her life, the woman confided in her mother, who then pressed charges against the aggressor.

P: Yes, it took away a part of me, and now I'm more afraid of people... When people say hello, men, I look down.

I: Things changed for you, you're more suspicious, you're more careful?

P: Yeah. It's dangerous you know. It could even be a serial killer, and I don't know it is. It could be super nice people, and then once you fall into their trap, you can't get out, and you're done for!

Among our study participants, only one (male) was both a target and a perpetrator of sexual cyber-solicitation.

I: What did you hide [from your parents] on Internet?

P: Well, things I had done, like... Like I can give you an example: I masturbated.

I: On webcam?

P: Yes.

I: With someone else?

P: Yes. There was a girl on the other side, well, on the webcam, looking at me.

His parents did find out eventually and took away his laptop computer to stop this behavior.

\section{Discussion}

There is a dearth of research on information and communication technology (ICT) use by people with ID or ASD. However small and preliminary, our study shows that people in this population do use ICT, have access to Internet, are eager to connect with other users, and want to be a part of the online community.

Differences in computer and Internet access or usage by people with disabilities compared with the general American population have been reported elsewhere and qualified as a digital divide (Fox, 2011; Normand et al., 
2016; Tanis et al., 2012; Tilley, Bruce, Hallam, \& Hills, 2006). However, all participants in our study were required to use a computer and navigate the Web to be eligible for sampling. While $2 / 8$ of our participants did not have an Internet connection at home, this figure is similar to that found for the general public $(2 / 10)$ in the Outaouais region in 2012 (Institut de la statistique du Québec [ISQ], 2013). House rules, self-control and cost were cited as obstacles to an Internet connection at home. In the Quebec population, lack of interest, of knowledge or of training, cost, and security concerns are raised to explain the lack of Internet connections at home (ISQ, 2013). In the U.S., age, income and education all impact the choice to invest or not in this technology, widening the divide for those who are older, less educated and low income earners (Rainie, 2016). Many of these factors apply to the majority of persons with disabilities, including ID and ASD.

Another difference is that $65 \%$ of adults of a similar age range (18-29 years $\left.{ }^{2}\right)$ in the general population own smartphones (Lenhart, 2013). In our sample, none of the five adults with ID had a smartphone, and only one in three with ASD did. Income has been reported as the greatest obstacle to ICT access by people with ID or other disabilities (Hoppestad, 2013). Although income was not measured, one participant did refer to cost as an obstacle to having an Internet connection at home. The lack of full-time employment of all our respondents (three were jobless, others worked part-time) leads us to hypothesize that the cost prevented the majority from investing in a mobile device and service contract.

Our study participants' online activities mirror those of the general population; however, people with ID used fewer opportunities offered by ICT and an Internet connection. For example, having cognitive limitations seems to hinder content creation online, whereas autistic traits do not. Among the few differences identified, shopping online appears less accessible to people with ID. Shopping online requires a credit card, which only two participants had. Also, young adults with ID or ASD are keen to meet a potential partner online. Although the use of dating sites is rising among young American adults, from 1 in 10 in 2013 to 27\% in 2015 (Smith \& Anderson, 2016), our sample subscribed to dating sites in a proportion of 5/8 (i.e. $62.5 \%$ ). The desire to meet a partner is surely explained by their very limited offline social circle, and the rarity of opportunities to actually go out and meet people without disabilities (Clement \& Bigby, 2009; Forrester-Jones et al., 2006). Another explanation may be that adults with disabilities like ID or ASD are more sensitive to rejection, and thus more likely to use online dating sites (Blackhart, Fitzpatrick, \& Williamson, 2014). Contrary to the general population, where men outnumber women on dating sites (Smith \& Duggan, 2013), in our preliminary study it is young women with ID or ASD (3/3) who appear most eager to develop long-term relationships and turn to this means. This may be a reflection of Quebec society, where women still earn less than men, and thus count on their support (Roy, 2016); more women than men are single (Roy, 2016); and womanhood may be defined by attractiveness or motherhood.

FB was the favourite of the SNS, just like in the general U.S. population (Lenhart, 2013), particularly among 18- to 29-year-olds (Rainie, 2013). Although published research has decried the fact that people with ID tend to accept practically anyone as an FB friend (Holmes \& O'Loughlin, 2012), being active on the most popular SNS does not bridge the social divide between people with disabilities and those without. Our study participants had a mean of 169 FB friends. This number is well below the average for American adults, of 338 (Lenhart, 2013). Furthermore, while half of 18- to 29-year-old FB users have more than 300 friends in their network (Smith, 2014), half of our sample had 100 or fewer. This suggests that people's online networks may be proportional to their offline ones. Perhaps people with ID or ASD receive fewer friend requests or, having been warned about the dangers, are more prudent when sending or accepting requests.

The way our subjects use FB resembles that presented in U.S. statistics from 2014. In both samples, people like watching what others post and "keeping in touch" through updates, but few receive support from their networks (Smith, 2014). While the way people with ID or ASD use SNS may seem rather passive, it is noteworthy that only $10 \%$ of neurotypical FB users change or update their FB status daily and that one in four say they never change or update it (Smith 2014). Whereas "sharing with many people at once" is the second most popular purpose of FB in the general population, it applied to only one study participant, with ASD but without ID, who had a mobile. It is unclear whether having a smartphone always turned on or having greater cognitive abilities, deeper interests and a richer environment is what increased her likelihood of participating more actively on SNS (she is also on Twitter, Instagram and Snapchat). 
Presence of unwanted sexual cyber-solicitation was confirmed for all female and three out of five male subjects. Unfortunately, we do not have comparable data from adults in the general population. Subscribing to online dating sites attracts such sexual demands from men, who report being more interested in sexual relationships, while women subscribers are more interested in long-term romantic relationships (Abramova, Baumann, Krasnova, \& Buxmann, 2016; Netimperative, 2012). It is unclear whether our subjects were aware of the risks associated with online dating (Baumgartner et al., 2010; Couch, Liamputtong, \& Pitts, 2012), but other studies report that the risk of being alone is perceived as greater than the risk of deceit or disappointment by people with ID and their caretakers (Löfgren-Mårtenson, 2008; Löfgren-Mårtenson et al., 2015; Seale, 2014). More disturbing may be the young man's masturbating in front of a girl online. Like many teenagers and adults with ID, he may have received little sex education and be unaware of the legal consequences of his actions (O'Callaghan, \& Murphy, 2007).

A theoretical model of virtual communities for people with long-term severe physical disabilities could well apply to these preliminary results (Tilley et al., 2006). According to this grounded theory study, people with long-term severe physical disabilities engage in virtual communities to gain a sense of control over their lives. ICT can compensate some of their physical limitations. It is unclear whether people with ID and ASD diagnoses (i.e. with socioemotional or intellectual limitations) would claim that Internet use gives them an added sense of control, but they can definitely exercise their self-determination by their choice of activities online. Furthermore, according to this theoretical model, there are six types of virtual communities: education, fantasy, information, interest, relationship and transaction. If any is lacking, then people experience only fragments of the virtual community. In light of this model, the gaps in the education, interest and transaction e-communities in our sample suggest that they may not benefit from the full virtual community experience.

\section{Study Limitations and Future Direction}

This exploratory study has several limitations. Although the very small sample provided us with a glimpse of Internet use by eight adults with ID or ASD, no generalizations can be made to the population of adults with similar disabilities. Differences between Internet users with ID versus ASD (without ID) must be interpreted very cautiously. Furthermore, no associations could be calculated between personal, social or environmental characteristics and Internet access, online activities or cyber-victimization. But several hypotheses that can guide future studies have emerged.

A representative sample of people with ID, people with ASD, and a matched comparison group of neurotypically developed subjects would allow us to test the "digital divide" hypothesis based on the theoretical model of virtual community participation proposed by Tilley and collaborators (2006). More detailed comparisons could be made, and the specific role of ID and ASD characteristics in Internet usage may be identified. Many variables, including gender, age, sexual orientation, income, educational attainment, loneliness, social isolation, impulsivity and self-esteem, have been identified as being related to the differential use of social media. These are worth measuring in future studies. Obstacles to digital accessibility, including cognitive demands, sensorimotor requirements, technical skills and social support (Normand et al., 2016), need to be taken into account when studying Internet use.

The fact that our youngest participant without ID and only one with a smartphone reported spending far more time online and described a much more varied use of social media and the Web begs the question: Are we witnessing a generation gap? Is intellectual disability the most important factor in explaining this discrepancy? Does the device determine Internet use and connectivity? If more people with ID became smartphone users, would some differences disappear and, if so, which ones?

The interview data also raise the issue of recall and social desirability in reporting time spent online, Internet use and choice of FB friends. Navigation data could provide true-to-life measures of the frequency, intensity, variety and quality of Internet use by these various populations. The subjects' online social network could be compared with their offline network as well.

Finally, cyberbullying experiences were neglected in favour of sexual cyber-solicitation in this report. Online bullying perpetration and victimization warrants attention since prevalence estimates of bullying among 
students with ID or ASD have yielded contradictory results (Maïano, Aimé, Salvas, Morin, \& Normand, 2015; Maïano, Normand, Salvas, Moullec, \& Aimé, 2015).

Much remains to be done is this area of research, not to mention education, prevention and intervention regarding Internet use by people with particular social and cognitive limitations, including ID and ASD. The needs of adults with ID in the face of navigating the web have been cruelly ignored. Many web sites have been designed to educate youth in safe Internet use (e.g. www.getcybersafe.gc.ca), but these require a high level of literacy and digital literacy, making them practically inaccessible to populations with cognitive impairments (Harrysson, Svensk, \& Johansson, 2004; Normand et al., 2016). Initiatives are being developed to adapt cyberbullying prevention programs to the population with ID (e.g. www.ojavolteface.ca/ultimatum-cyber-intimidation). However, the United Nations have argued that sanctions be put in place to protect users by punishing abusers and neglectful or harmful Internet providers or websites, rather than place the burden on victims to protect themselves or restrict their access to the web to ensure their safety (UN Broadband Commission for Digital Development, 2015). In this digital age, the participation of people with ID or ASD as global citizens needs to be encouraged and supported to prevent further inequalities and a widening digital divide.

\section{Notes}

1. Having subscribed to dating sites may have made these study participants more prone to such encounters. This is why it is important to specify that they were asked about unwanted sexual solicitation.

2. Seven of our eight study participants were between 19 and 30 years old.

\section{Acknowledgement}

This study was made possible in part by the financial support of the Consortium National de Recherche sur I'Intégration Sociale, Trois-Rivières, Québec, Canada, through a doctoral scholarship to F. Sallafranque St-Louis.

\section{References}

Abramova, O., Baumann, H., Krasnova, H., \& Buxmann, P. (2016). Gender differences in online dating: what do we know so far? A systematic literature review. 49th Hawaii International Conference on System Sciences.

http://dx.doi.org/10.1109/HICSS.2016.481

Amichai-Hamburger, Y. (Ed.). (2013). The social net: Human behavior in cyberspace (2nd ed.). New York, NY: Oxford University Press.

Baumgartner, S. E., Valkenburg, P. M., \& Peter, J. (2010). Unwanted online sexual solicitation and risky sexual online behavior across the lifespan. Journal of Applied Developmental Psychology, 31, 439-447.

http://dx.doi.org/10.1016/j.appdev.2010.07.005

Blackhart, G. C., Fitzpatrick, J., \& Williamson, J. (2014). Dispositional factors predicting use of online dating sites and behaviors related to online dating. Computers in Human Behavior, 33, 113-118.

http://dx.doi.org/10.1016/j.chb.2014.01.022

Blais, M., \& Martineau, S. (2006). L'analyse inductive générale: Description d'une démarche visant à donner un sens à des données brutes. [General inductive analysis: Description of a process aimed at making sense of raw data]. Recherches qualitatives [Qualitative Research], 26(2), 1-18.

Blaya, C. (2015). Les jeunes et les prises de risque sur Internet. [Youth and risk taking on the Internet.] Neuropsychiatrie de l'enfance et de l'adolescence [Childhood and Adolescence Neuropsychiatry], 63, 518-523. http://dx.doi.org/10.1016/j.neurenf.2015.07.003

Brereton A. V., Tonge B. J., \& Stewart L. E. (2006). Psychopathology in children and adolescents with autism compared to young people with intellectual disability. Journal of Autism \& Developmental Disorders, 36, 863-870. http://dx.doi.org/10.1007/s10803-006-0125-y 
Buijs, P. C. M., Boot, E., Shugar, A., Fung, W. L. A., \& Bassett, A. S. (2016). Internet safety issues for adolescents and adults with intellectual disabilities. Journal of Applied Research in Intellectual Disabilities 30, 416-418.

http://dx.doi.org/10.1111/jar.12250

Cambridge P., Carpenter J., Beecham J., Hallam A., Knapp M., \& Forrester-Jones R. (2002). Twelve years on: The long term outcomes and costs of deinstitutionalisation and community care for people with learning disabilities. Tizard Learning Disability Review, 7, 34-42. http://dx.doi.org/10.1108/13595474200200027

Caton, S. \& Chapman, M. (2016). The use of social media and people with intellectual disability: A systematic review and thematic analysis. Journal of Intellectual and Developmental Disability, 41, 125-139.

http://dx.doi.org/10.3109/13668250.2016.1153052

Chadwick, D., Wesson, C., \& Fullwood, C. (2013). Internet access by people with intellectual disabilities: Inequalities and opportunities. Future Internet, 5, 376-397. http://dx.doi.org/10.3390/fi5030376

Clement, T., \& Bigby, C. (2009). Breaking out of a distinct social space: Reflections on supporting community participation for people with severe and profound intellectual disability. Journal of Applied Research in Intellectual Disabilities, 22, 264-275. http://dx.doi.org/10.1111/j.1468-3148.2008.00458.x

Couch, D., Liamputtong, P., \& Pitts, M. (2012). What are the real and perceived risks and dangers of online dating? Perspectives from online daters. Health, Risk \& Society, 14, 697-714.

http://dx.doi.org/10.1080/13698575.2012.720964

Didden, R., Scholte, R. H. J., Korzilius, H., De Moor, J. M. H., Vermeulen, A., O'Reilly, M., . . Lancioni, G. E. (2009). Cyberbullying among students with intellectual and developmental disability in special education settings. Developmental Neurorehabilitation, 12, 146-151. http://dx.doi.org/10.1080/17518420902971356

Dowdell, E. B. (2013). Use of the Internet by parents of middle school students: Internet rules, risky behaviours and online concerns. Journal of Psychiatric and Mental Health Nursing, 20(1), 9-16. http://dx.doi.org/10.1111/j.13652850.2011.01815.x

Forrester-Jones R., Carpenter J., Coolen-Schrijner P., Cambridge P., Tate A., \& Beecham J. (2006) The social networks of people with intellectual disability living in the community 12 years after resettlement from long-stay hospitals. Journal of Applied Research in Intellectual Disabilities 19, 285-295. http://dx.doi.org/10.1111/j.14683148.2006.00263.x

Fox, S. (2011). Americans living with disability and their technology profile. Pew Research Center. Retrieved from http://www.pewinternet.org/2011/01/21/americans-living-with-disability-and-their-technology-profile/

García-Galera, M.-C., Del-Hoyo-Hurtado, M., \& Fernández-Muñoz, C. (2014). Engaged youth in the Internet. The role of social networks in social active participation. Comunicar, 22(43), 35-43. http://dx.doi.org/10.3916/C432014-03

Giard, M-F., \& Morin, D. (2010). Le consentement à la recherche en déficience intellectuelle: Situation québécoise [Consent to research in intellectual disability: The situation in Quebec]. Revue Francophone de la Déficience Intellectuelle [Francophone Journal of Intellectual Disability], 21, 40-53.

Gohier, C. (2004). De la démarcation entre critères d'ordre scientifique et d'ordre éthique en recherche interprétative. [Setting boundaries between scientific and ethical criteria in interpretive research]. Recherches Qualitatives [Qualitative Research], 24, 3-17

Guan, S.-S. A., \& Subrahmanyam, K. (2009). Youth Internet use: Risks and opportunities. Current Opinion in Psychiatry, 22, 351-356. http://dx.doi.org/10.1097/YCO.0b013e32832bd7e0

Harrysson, B., Svensk, A., \& Johansson, G.I. (2004). How people with developmental disabilities navigate the Internet. British Journal of Special Education, 31, 138-142. http://dx.doi.org/10.1111/j.0952-3383.2004.00344.x

Helweg-Larsen, K., Schütt, N., \& Larsen, H. B. (2012). Predictors and protective factors for adolescent Internet victimization: Results from a 2008 nationwide Danish youth survey. Acta Paediatrica, 101, 533-539.

http://dx.doi.org/10.1111/j.1651-2227.2011.02587.x 
Ho, R. C., Zhang, M. W. B., Tsang, T. Y., Toh, A. H., Fang, P., Yanxia, L., .. Kwok-Kei, M. (2014). The association between internet addiction and psychiatric co-morbidity: A meta-analysis. Bio Med Central [BMC] Psychiatry, 14, 284-306. http://dx.doi.org/10.1186/1471-244X-14-183

Holmes, K. M., \& O'Loughlin, N. (2012). The experiences of people with learning disabilities on social networking sites. British Journal of Learning Disabilities, 42, 3-7. http://dx.doi.org/10.1111/bld.12001

Hoppestad, B. S. (2013). Current perspective regarding adults with intellectual and developmental disabilities accessing computer technology. Disability \& Rehabilitation: Assistive Technology, 8, 190-194.

http://dx.doi.org/10.3109/17483107.2012.723239

Institut de la statistique du Québec [ISQ] (2013). L'Enquête québécoise sur l'accès des ménages à Internet 2012. Présentation et analyse des résultats. [2012 Québec Household Internet Access Survey. Results presentation and analysis.] Québec, QC: Gouvernement du Québec.

Internet World Stats (2016). World internet usage and population statistics June 30, 2016 - update. Retrieved from http://www.internetworldstats.com/stats.htm

Kampert, A. L., \& Goreczny, A. J. (2007). Community involvement and socialization among individuals with mental retardation. Research in Developmental Disabilities, 28, 278-286. http://dx.doi.org/10.1016/j.ridd.2005.09.004

Khemka I., \& Hickson L. (2000). Decision-making by adults with mental retardation in simulated situations of abuse. Mental Retardation, 38, 15-26. http://dx.doi.org/10.1352/0047-6765(2000)038<0015:DBAWMR>2.0.CO;2

Kydland, F., Molka-Danielson, J., \& Balandin, S. (2012, November). Examining the use of social media tool "Flickr" for impact on loneliness for people with intellectual disability. Paper presented at Norsk konferanse for organisasjoners bruk av informasjonsteknologi, Bodo, Norway. Retrieved from http://dro.deakin.edu.au/eserv/DU:30062177/balandin-examininguseof-2012.pdf

Lenhart, A. (2013). Young adults, mobile phones and social media: Technology and the transition to adulthood. Pew Research Center. Retrieved from http://www. pewinternet.org/2013/05/07/young-adults-mobile-phones-andsocial-media-technology-and-the-transition-to-adulthood/

Livingstone, S., Haddon, L., Görzig, A., \& Ólafsson, K. (2011). Risks and safety on the internet: The perspective of European children. Full Findings. London, UK: EU Kids Online.

Löfgren-Mårtenson, L. (2008). Love in cyberspace: Swedish young people with intellectual disabilities and the Internet. Scandinavian Journal of Disability Research, 10, 125-138. http://dx.doi.org/10.1080/15017410701758005

Löfgren-Mårtenson, L., Sorbring, E., \& Molin, M. (2015). "T@ngled up in blue": Views of parents and professionals on Internet use for sexual purposes among young people with intellectual disabilities. Sexuality \& Disability, 33, 533-544. http://dx.doi.org/10.1007/s11195-015-9415-7

Lussier-Desrochers, D., Dupont, M.-E., Lachapelle, Y., \& Leblanc, T. (2011). Étude exploratoire sur l'utilisation de I'Internet par les personnes présentant une déficience intellectuelle. [Exploratory study on Internet use by people with an intellectual disability.] Revue francophone de la déficience intellectuelle [Francophone Journal of Intellectual Disability], 22, 41-50.

MacMullin, J. A., Lunsky, Y., \& Weiss, J. A. (2016). Plugged in: Electronics use in youth and young adults with autism spectrum disorder. Autism: The International Journal of Research and Practice, 20, 45-54.

http://dx.doi.org/10.1177/1362361314566047

Maïano, C., Aimé, A., Salvas, M.-C., Morin, A. J. S., \& Normand, C. L., (2015). Prevalence and correlates of bullying perpetration and victimization among school-aged youth with intellectual disabilities: A systematic review. Research in Developmental Disabilities, 49-50, 181-195. http://dx.doi.org/10.1016/j.ridd.2015.11.015

Maïano, C., Normand, C.L., Salvas, M.-C., Moullec, G., \& Aimé, A. (2015). Prevalence of school bullying among youth with autism spectrum disorders: A systematic review and meta-analysis. Autism Research, 9, 601-615. http://dx.doi.org/10.1002/aur.1568 
Mandell, D. S., Walrath, C. M., Manteuffel, B., Sgro, G., \& Pinto-Martin, J. A. (2005). The prevalence and correlates of abuse among children with autism served in comprehensive community-based mental health settings. Child Abuse \& Neglect, 29, 1359-1372. http://dx.doi.org/10.1016/j.chiabu.2005.06.006

McClimens, A., \& Gordon, F. (2009). People with intellectual disabilities as bloggers: What's social capital got to do with it anyway? Journal of Intellectual Disabilities, 13, 19-30. http://dx.doi.org/10.1177/1744629509104486

McGillivray, A. J., \& McCabe, P. M. (2005). Early detection of depression and associated risk factors in adults with mild/moderate intellectual disability. Research in Developmental Disabilities, 28, 59-70.

http://dx.doi.org/10.1016/j.ridd.2005.11.001

Moisey, S., \& van de Keere, R. (2007). Inclusion and the Internet: Teaching adults with developmental disabilities to use information and communication technology. Developmental Disabilities Bulletin, 35, 72-102.

Molin, M., Sorbring, E., \& Löfgren-Mårtenson, L. (2015). Teachers' and parents' views on the Internet and social media usage by pupils with intellectual disabilities. Journal of Intellectual Disabilities, 19, 22-33.

http://dx.doi.org/10.1177/1744629514563558

Murphy, G. H., \& O'Callaghan, A. C. (2004). Capacity of adults with intellectual disabilities to consent to sexual relationships. Psychological Medicine, 34, 1347-1357. http://dx.doi.org/10.1017/S0033291704001941

Netimperative (2012, February 8). Online dating: New eye-tracking research shows what men and women really want. Netimperative. Retrieved from http://www.netimperative.com/2012/02/online-dating-new-eye-tracking-researchshows-what-men-and-women-really-want/

Nettlebeck, T., \& Wilson, C. (2002). Personal vulnerability to victimization of people with mental retardation. Trauma, Violence \& Abuse, 3, 289-306.

Noll, J. G., Shenk, C. E., Barnes, J. E., \& Haralson, K. J. (2013). Association of maltreatment with high-risk internet behaviors and offline encounters. Pediatrics, 131, 510-517. http://dx.doi.org/10.1542/peds.2012-1281

Noll, J. G., Shenk, C. E., Barnes, J. E., \& Putnam, F. W. (2009). Childhood abuse, avatar choices, and other risk factors associated with Internet-initiated victimization of adolescent girls. Pediatrics, 123, 1078-1083.

http://dx.doi.org/10.1542/peds.2008-2983

Normand, C. L., Lussier-Desrochers, D., Fecteau, S. M., Godin-Tremblay, V., Dupont, M.-È., Roux, J., \& RomeroTorres, A. (2016). Factors leading to the digital exclusion of people with neurodevelopmental disorders: A conceptual model. Annual Review of Cybertherapy and Telemedicine, 14, 23-29.

Normand, C. L., \& Sallafranque St-Louis, F. (2015). Cybervictimization of young people with an intellectual or developmental disability: Risks specific to sexual solicitation. Journal of Applied Research in Intellectual Disabilities, 29, 99-110. http://dx.doi.org/10.1111/jar.12163

O'Callaghan, A. C., \& Murphy, G. H. (2007), Sexual relationships in adults with intellectual disabilities: Understanding the law. Journal of Intellectual Disability Research, 51, 197-206. http://dx.doi.org/10.1111/j.13652788.2006.00857.x

Paillé, P., \& Mucchielli, A. (2012). L'analyse qualitative en sciences humaines et sociales. [Qualitative analysis in humanities and social sciences] (2nd ed.). Paris: Armand Colin.

Raghavendra, P., Newman, L., Grace, E., \& Wood, D. (2013). "I could never do that before": Effectiveness of a tailored Internet support intervention to increase the social participation of youth with disabilities. Child: Care, Health \& Development, 39, 552-561. http://dx.doi.org/10.1111/cch.12048

Rainie, L. (2016). Digital divides 2016. Pew Research Center. Retrieved from

http://www.pewinternet.org/2016/07/14/digital-divides-2016/

Rainie, L. (2013). The state of Facebook. Pew Research Center. Retrieved from http://www.pewinternet.org/2013/03/14/the-state-of-facebook/

Roy, N. (2016). Portrait des Québécoises en 8 temps. [Portrait of Québec women in eight counts.] Québec, QC: Conseil du Statut de la Femme. 
Sallafranque St-Louis, F. \& Normand, C. L. (2011). La sollicitation sexuelle sur Internet auprès des jeunes ayant un retard de développement. [Sexual solicitation on the Internet of youth with development delays.] Revue québécoise de psychologie [Québec Journal of Psychology], 32(1), 1-14.

Seale, J. (2014). The role of supporters in facilitating the use of technologies by adolescents and adults with learning disabilities: A place for positive risk-taking? European Journal of Special Needs Education, 29, 220-236. http://dx.doi.org/10.1080/08856257.2014.906980

Shpigelman, C.-N., \& Gill, C. J. (2014). How do adults with intellectual disabilities use Facebook? Disability \& Society, 29, 1601-1616. http://dx.doi.org/10.1080/09687599.2014.966186

Smith, A. (2014). 6 new facts about Facebook. Pew Research Center. Retrieved from http://www.pewresearch.org/fact-tank/2014/02/03/6-new-facts-about-facebook/

Smith, A., \& Anderson, M. (2016). 5 facts about online dating. Pew Research Center. Retrieved from http://www.pewresearch.org/fact-tank/2016/02/29/5-facts-about-online-dating/

Smith, A., \& Duggan, M. (2013). Part 2: Dating apps and online dating sites. Pew Research Center. Retrieved from http://www.pewinternet.org/2013/10/21/part-2-dating-apps-and-online-dating-sites/

Stake, R. E. (2006). Multiple case study analysis. New-York, NY: The Guildford Press.

Subrahmanyam, K., Greenfield, P. M., \& Brendesha, T. (2004). Constructing sexuality and identity in an online teen chat room. Applied Developmental Psychology, 25, 651- 666. http://dx.doi.org/10.1016/j.appdev.2004.09.007

Suzuki, K., Asaga, R., Sourander, A., Hoven, C. W., \& Mandell, D. (2012). Cyberbullying and adolescent mental health. International Journal of Adolescent Medicine and Health, 24, 27-35.

http://dx.doi.org/10.1515/ijamh.2012.005

Tanis, E. S., Palmer, S., Wehmeyer, M., Davies, D. K., Stock, S. E., Lobb, K., \& Bishop, B. (2012). Self-report computer-based survey of technology use by people with intellectual and developmental disabilities. Intellectual and Developmental Disabilities, 50, 53-68. http://dx.doi.org/10.1352/1934-9556-50.1.53

Tilley, C. M., Bruce, C. S., Hallam, G., \& Hills, A. P. (2006). A model for the development of virtual communities for people with long-term, severe physical disabilities. Information Research, 11(3), paper 253. Retrieved from http://InformationR.net/ir/11-3/paper253.html

UN Broadband Commission for Digital Development Working Group on Broadband and Gender (2015). Cyber violence against women and girls. UN Women, UNDP and ITU. Retrieved from

http://www.unwomen.org/en/digital-library/publications/2015/9/cyber-violence-against-women-and-girls

Wells, M., \& Mitchell, K. J. (2014). Patterns of internet use and risk of online victimization for youth with and without disabilities. The Journal of Special Education, 48, 204-213. http://dx.doi.org/10.1177/0022466913479141

Ybarra, M. L. (2004). Linkages between depressive symptomatology and Internet harassment among young regular Internet users. CyberPsychology \& Behavior, 7, 247-257. http://dx.doi.org/10.1089/109493104323024500

Ybarra, M. L., Espelage, D. L., \& Mitchell, K. J. (2007). The co-occurrence of Internet harassment and unwanted sexual solicitation victimization and perpetration: Associations with psychosocial indicators. Journal of Adolescent Health, 41, 31-41. http://dx.doi.org/10.1016/j.jadohealth.2007.09.010

Ybarra, M. L., Mitchell, K. J., Palmer, N. A., \& Reisner, S. L. (2014). Online social support as a buffer against online and offline peer and sexual victimization among U.S. LGBT and non-LGBT youth. Child Abuse \& Neglect, 39, 123136. http://dx.doi.org/10.1016/j.chiabu.2014.08.006

Young, K. S. (2009). Internet addiction: The emergence of a new clinical disorder. CyberPsychology \& Behavior, 1 , 237-244. http://dx.doi.org/10.1089/cpb.1998.1.237 


\section{Correspondence to:}

Claude L. Normand

Department of Psychoeducation and Psychology

Université du Québec en Outaouais

P.O. Box 1250

Station Hull

Gatineau

Québec J8X 3X7

Canada

Email: Claude.normand@uqo.ca

\section{About Authors}

Dr. François Sallafranque St-Louis is a Psychologist at the Centre intégré de santé et de services sociaux de I'Outaouais, Gatineau, Canada. His research interests lie in social inclusion and participation of people with intellectual or developmental disabilities and the issues faced by the LGBT community.

Dr. Claude L. Normand is Associate Professor in Psychoeducation and Psychology at the Université du Québec en Outaouais, in Gatineau, Canada. Her research focuses on inclusion and social participation, online and offline, of people with intellectual or developmental disabilities.

Editorial record: First submission received on September 9, 2016. Revision received on February 14, 2017. Accepted for publication on May 5, 2017. The article is part of Special Issue "Internet use and disability - Risks, opportunities and challenges" guest edited by Emma Sorbring and Martin Molin. 